\title{
Effect of Drug Targeting Nebulization on Lung Deposition: A Randomized Crossover Scintigraphic Comparison Between Central and Peripheral Delivery
}

\author{
Gregory Reychler PhD PT, Anne-Sophie Aubriot PT, Virginie Depoortere, \\ François Jamar $\mathrm{PhD} \mathrm{MD}$, and Giuseppe Liistro $\mathrm{PhD} \mathrm{MD}$
}

\begin{abstract}
BACKGROUND: Recent technological advances in nebulization permit researchers to target specific parts of the lungs by modifying delivery method. The aim of this study was to compare the central and peripheral targeted modalities of administration. METHODS: Lung and regional deposition of inhaled technetium-99m diethylene triamine penta-acetic was measured by scintigraphy after peripheral and central targeted modalities of administration with an Akita device in 6 healthy subjects. RESULTS: Drug targeting nebulization delivered a large amount of drug into the peripheral part of the lung independent of the modality (outer-to-inner deposition ratio of $1.24 \pm 0.21$ vs $1.22 \pm 0.14$ for central and peripheral modalities, respectively), but there was no difference in lung deposition (whole-body deposition, $83.3 \pm 6.5 \%$ vs $82.8 \pm 7.3 \%, P=.86$ ) or regional deposition $(P=.77)$ between both modalities. The extrathoracic deposition was $<20 \%$ of the wholebody deposition, without a difference between modalities $(P=.86)$. CONCLUSIONS: This study shows for the first time that choosing 2 different specific drug targeting nebulization modes does not influence the amount of drug delivered into the lung in healthy male subjects. Moreover, the modes do not modify the site of deposition under the conditions of our study. Key words: nebulizer; deposition; imagery; breathing pattern. [Respir Care 2014;59(10):1501-1507. (C) 2014 Daedalus Enterprises]
\end{abstract}

\section{Introduction}

Nebulizations are regularly prescribed for patients who suffer from respiratory disease. When indicated, a high efficiency is required. Efficacy of specific drugs unavailable by administration methods other than nebulization was demonstrated. Moreover, some drugs such as antibiotics may have narrow windows of efficacy, which means that they need to be delivered efficiently and reproducibly. ${ }^{1}$ Repeated courses of high doses of inhaled antibiot-

\footnotetext{
Drs Reychler and Liistro are affiliated with the Institut de Recherche Expérimentale et Clinique, Pôle de Pneumologie, ORL et Dermatologie, Université Catholique de Louvain, Brussels, Belgium. Drs Reychler and Liistro are also affiliated with the Service de Pneumologie, Ms Aubriot is affiliated with the Centre de Référence pour la Mucoviscidose, and Ms Depoortere and Dr Jamar are affiliated with the Service de Médecine Nucléaire, Cliniques Universitaires Saint-Luc, Université Catholique de Louvain, Brussels, Belgium.
}

The authors have disclosed no conflicts of interest. ics have been increasingly applied in cystic fibrosis. ${ }^{2} \mathrm{Neb}-$ ulized tobramycin was demonstrated to be effective by improving lung function ${ }^{3}$ and by reducing sputum $\mathrm{Pseu}^{\mathrm{S}}$ domonas aeruginosa density, ${ }^{3}$ number of hospitalizations, ${ }^{4}$ and frequency of antibiotics administration. ${ }^{5}$ Classically, the efficacy of an inhaled antibiotic is related to the amount delivered to the target site. In particular, alveolar deposition takes advantage of the greater absorptive surface, the absence of mucociliary clearance, and the thin barrier to systemic absorption related to this region compared with a more proximal deposition. Targeting aerosol distribution according to receptor distribution within the airways and

Correspondence: Gregory Reychler PhD PT, Pneumology Unit, Cliniques
Universitaires Saint-Luc, Université Catholique de Louvain, Avenue Hip-
pocrate 10, 1200 Brussels, Belgium. E-mail: gregory.reychler@uclouvain.be.

DOI: $10.4187 /$ respcare. 03068 


\section{Drug Targeting Nebulization and Lung Deposition}

therefore the site of action of the drug is, of course, attractive. ${ }^{6}$

A consensus on inhalation in patients with cystic fibrosis highlighted the differences in lung administration depending on the chosen device and the importance of the quality of the nebulizer. ${ }^{7}$ The first generations of nebulizers deposited variable drug amounts ${ }^{8,9}$ (between $5^{10}$ and $30 \%{ }^{11}$ of the nominal dose) and often mainly in the central airways, ${ }^{12}$ depending on the devices, lung function, and age of the subjects. More efficient modalities of administration are required for patients presenting with lung impairment, infection, or small airway obstruction. Two main categories of parameters can be modified to improve drug administration into the lungs. First, parameters related to the patients can be optimized. Indeed, lung deposition has been previously demonstrated to be related to the pattern of breathing. ${ }^{13-16}$ Second, the modality of administration and the device play a role in the efficiency of administration. ${ }^{16,17}$

New devices and technologies regularly appear on the market. ${ }^{18}$ Recently, dosimetric and adaptive deliveries completed the available devices. These modalities are designed to select timing of administration. Indeed, the drug is delivered during inspiration or even during only a specific period of the inspiration, depending on the nebulized drug (drug targeting nebulization). The new Akita devices (Activaero, Gemünden, Germany) include the control of a specific inhalation pattern, similar to adaptive nebulizers. They improve lung deposition. Indeed, they may deposit $>60 \%$ the nominal dose into the lungs. ${ }^{19}$ Moreover, they are able to target the peripheral parts of the lungs by modifying the delivery method. ${ }^{20,21}$ The aim of this study was to quantify total and peripheral lung deposition by drug targeting nebulization and to compare the peripheral and central targeted modalities of administration.

\section{Methods}

\section{Subjects}

Six healthy nonsmoking male volunteers were recruited for the study. Only males were chosen to avoid different anterior and posterior chest wall attenuation related to the breast tissue. ${ }^{22}$ They signed a written informed consent form in accordance with the Declaration of Helsinki and with current guidelines for Clinical Good Practice. The study was previously approved by the institutional medical ethics committee. Exclusion criteria included a history or evidence of cardiovascular or pulmonary disease and an abnormal pulmonary function test.

Each subject was in good health (eg, physical examination, vital signs, medical history) at the time of the study. They performed spirometry according to the American Thoracic Society/European Respiratory Society guide-

\section{QUICK LOOK}

\section{Current knowledge}

Advances in nebulization allow targeting either central or peripheral drug deposition based on the drug and desired site of activity. This scheme requires different nebulization devices and aerosol characteristics.

\section{What this paper contributes to our knowledge}

In healthy male subjects, targeting nebulization modes does not influence the amount of drug delivered into the lung. The selected modes do not modify the site of deposition.

lines. ${ }^{23}$ The subjects had not received any aerosolized drug during the month preceding the experiments.

\section{Design}

The study was conducted in 5 steps for each volunteer: (1) selection visit, spirometry, and medical examination; (2) demonstration of nebulizer functioning and training to inhale slowly; (3) scintigraphic study with inhaled krypton gas $\left({ }^{81 \mathrm{~m}} \mathrm{Kr}\right) ;(4)$ nebulization of a diethylene triamine pentaacetic (DTPA) solution ( $\left.{ }^{99 \mathrm{~m}} \mathrm{Tc}-\mathrm{DTPA}\right)$; and (5) scintigraphic study. Each subject repeated this procedure using a randomized crossover setting for both modalities of administration with a 96-h washout period between the 2 procedures. The 2 procedures were randomized (Fig. 1) by a computer-generated random number list. The subjects were blinded, and they knew only the number of inhalations.

\section{Nebulization Modalities}

An Akita device, which is a computer-controlled jet nebulizer allowing individualized and controlled inhalation, was used. The jet nebulizer (based on the LC Sprint nebulizer, Pari GmbH, Starnberg, Germany) is triggered by the device, and a compressor is integrated into the Akita to deliver the driving pressure. The inhalation flow, the inhaled volume, and the number of inhalations can be precisely predetermined with a controlled regulation of aerosolized drugs during the inspiration depending on the targeted site of deposition. The 2 settings provided by the manufacturer are targeting central and peripheral deposition. This is done by varying the sequence of air or drug administration during inspiration (Fig. 2). In this study, an inspiration of $4 \mathrm{~s}$ was preset for both modalities. Based on previous in vitro experiments, the number of inspirations was fixed to 62 and 93 for peripheral and central deposi- 


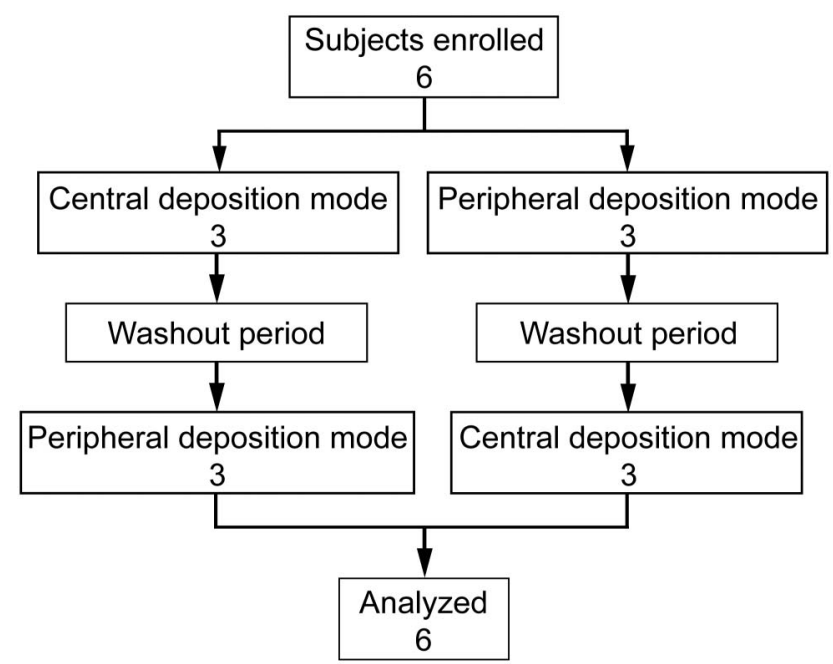

Fig. 1. Study enrollment, random assignment, and analysis.
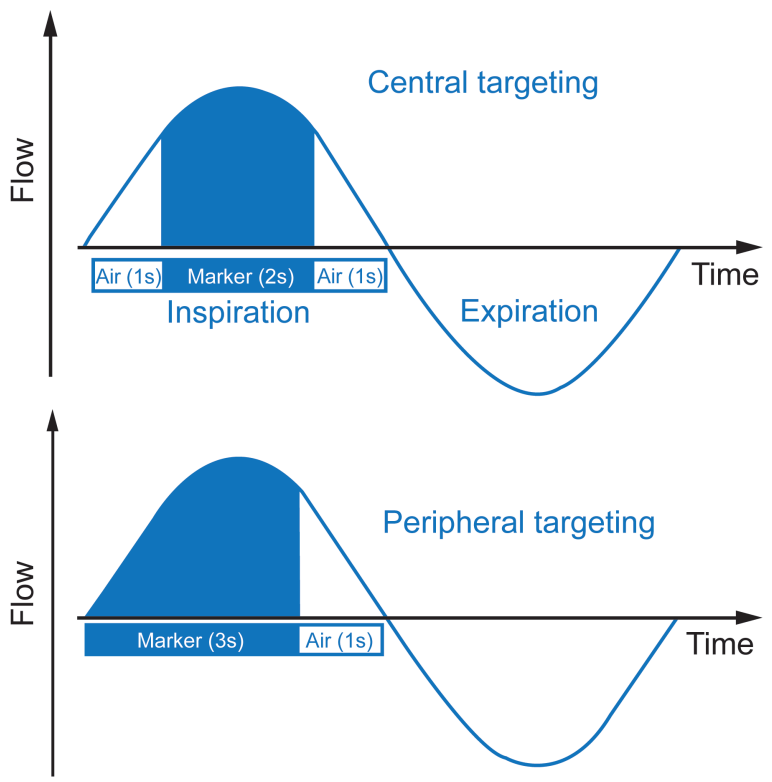

Fig. 2. Illustration of central and peripheral targeting nebulization modalities during 1 inspiratory cycle.

tion, respectively. This corresponds to a tidal volume of $0.8 \mathrm{~L}$. These modalities assumed the same delivered amount at the end of the program. During the nebulization, the subjects were comfortably seated and breathed through the mouthpiece, wearing a nose clip. The nebulizations were performed randomly at the same time of the day, in the same room, and at ambient temperature $\left(22^{\circ} \mathrm{C}\right)$.

\section{Nebulization Procedure}

First, ${ }^{81 \mathrm{~m}} \mathrm{Kr}$ gas $\left({ }^{81} \mathrm{Rb}^{8}{ }^{81 \mathrm{~m}} \mathrm{Kr}\right.$ generator, Covidien, Petten, The Netherlands) was inhaled by the subjects. The gas was administered continuously during tidal breathing with a face mask to delineate the lung volume.

Second, the nebulizer was loaded with a 4-mL solution of ${ }^{99 \mathrm{~m}}$ Tc-DTPA (TechneScan DTPA, Mallinckrodt, Petten, The Netherlands). The initial activity was measured with a CRC-12 radioisotope calibrator (Capintec, Pittsburgh, Pennsylvania) and was $2.06 \pm 0.11 \mathrm{mCi}$. A filter $(\mathrm{Hy}-$ grovent, Medisize, Hillegom, The Netherlands) was connected with a one-way valve to the nebulizer systems to avoid ambient aerosol contamination and to measure the total activity recovered during the expiration. No ambient or surface contamination was detected after the procedures. The same procedure was repeated for both modalities. The subjects followed the instructions for inhalation provide with the device. The stop time was determined by the settings of the program.

\section{Image Acquisition}

The assessor did not know which nebulization the subject had performed. During the ${ }^{81 \mathrm{~m}} \mathrm{Kr}$ inhalation and before the nebulization, each subject was seated close to the acquisition field of the gamma camera to record a posterior view of the thorax to delineate the lung volume. Image acquisition was performed for 2 min with a planar singledetector gamma camera (Starport 400 AC/T, GE Healthcare, Horsholm, Denmark) equipped with a 390-mm lowenergy, high-resolution collimator. The camera was calibrated monthly for uniformity (useful field of view of $370 \mathrm{~mm}$ and central field of view of $278 \mathrm{~mm}$ ).

Imaging was performed based on the recent standardization of planar imaging for aerosol deposition. ${ }^{24}$ Images were acquired using a $128 \times 128$ matrix for 1 or 2 min for the device (including the nebulizer and filter) and airways, respectively. The spatial resolution of this system is $5.3 \mathrm{~mm}$ at $10 \mathrm{~cm}$.

Immediately after the nebulization, the subjects were seated in front of the head of the gamma camera, and 4 images were recorded: (1) a posterior and (2) an anterior view of the thorax to image aerosol deposition in the stomach and lungs, (3) a lateral view of the oropharyngeal region, and (4) the residual activity in the nebulizer and filter.

\section{Image Analysis}

Gamma camera images were analyzed (Odyssey LR 7.01.7, Philips Healthcare, Best, The Netherlands) by a blinded trained technologist. The whole-body deposition was calculated by adding the activity of the right and left lungs, stomach, esophagus, mouth, and oropharynx, taking into account gamma camera attenuation, background, and radioactive decay. 


\section{Drug Targeting Nebulization and Lung Deposition}

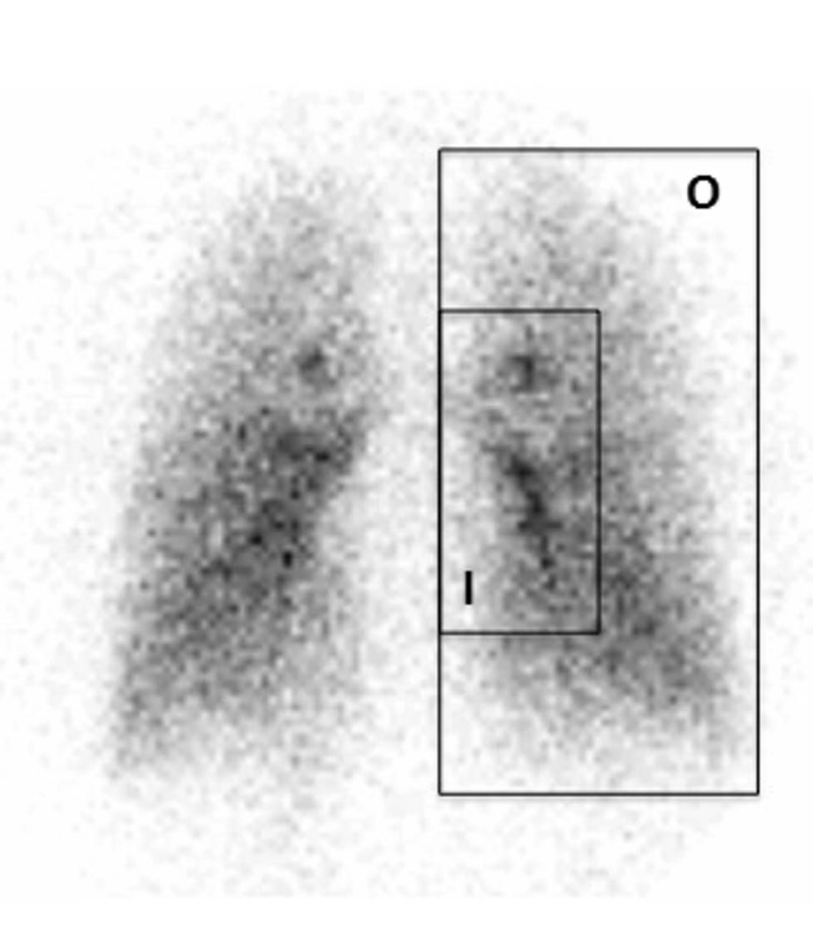

Fig. 3. Regions of interest determined by the 2-compartment model. $\mathrm{I}=$ inner region; $\mathrm{O}=$ outer region.

First, the lung activity was calculated. The regions of interest of the lungs were defined from the lung outline by ${ }^{81 \mathrm{~m}} \mathrm{Kr}$ ventilation images. Second, they were applied to the images obtained by ${ }^{99 \mathrm{~m}} \mathrm{Tc}$ images. A whole-lung rectangle was drawn around the lung at the boundaries of the ventilation scan to measure the intrapulmonary deposition. Intrapulmonary deposition was expressed as a percentage of the whole-body deposition. The regional deposition was assessed for the right lung. Inner (I) and outer (O) regions of interest were determined by the 2-compartment model (Fig. 3). ${ }^{24}$ An I region with dimensions equal to half of the width of the whole-lung rectangle and half of its height was positioned on the interior boundary of the lung, centered by height. The I region is then $25 \%$ of the area of the whole-lung rectangle. The $\mathrm{O}$ region is the area lying between the inner and whole-lung rectangles and has an area of $75 \%$ of the whole-lung rectangle. The geometric mean of anterior and posterior counts was calculated by the square root of the multiplication of these counts. From there, the ratio of outer lung deposition to inner lung deposition $(\mathrm{O} / \mathrm{I})$ was calculated. This ratio was normalized by dividing by the corresponding ratio for the radioactive gas scan, and it is referred to as the penetration index.

The extrathoracic deposition was calculated by adding the activity measured in the oropharyngeal regions, esophagus, trachea, and stomach with the assumption that ac-
Table 1. Anthropometric and Spirometric Data of 6 Healthy Male Subjects

\begin{tabular}{lc}
\hline \hline & Mean \pm SD \\
\hline Age, $y$ & $30.3 \pm 16.4$ \\
Height, cm & $175.6 \pm 1.9$ \\
Weight, $\mathrm{kg}$ & $81.4 \pm 11.3$ \\
BMI, $\mathrm{kg} / \mathrm{m}^{2}$ & $26.4 \pm 3.6$ \\
$\mathrm{FVC}, \%$ of predicted & $95.7 \pm 3.3$ \\
$\mathrm{FEV}_{1}, \%$ of predicted & $96.8 \pm 6.0$ \\
$\mathrm{FEV}_{1} / \mathrm{FVC}$ & $1.01 \pm 0.06$
\end{tabular}

$\mathrm{BMI}=$ body mass index

tivity in the stomach resulted from nasal clearance and pharyngeal deposition during inhalation. Results were expressed as a percentage of the whole-body deposition. The residual activity was measured in the nebulizer at the end of the nebulization.

For quality assurance, the mass balance was calculated by the ratio between the acquired counts from the lungs, extrathoracic regions, residual dose, and exhalation filter and the total expected radioactivity. The mean mass balance was checked to be within $100 \pm 10 \% .{ }^{24}$

\section{Statistics}

The sample size needed for detecting a 10\% difference in peripheral deposition at a 5\% significance level for a 2 -sided test with $90 \%$ power was determined based on previous data $(n=5)$. Results are expressed as mean \pm SD. Statistical tests were performed using SPSS Statistics 20.0 (IBM, Bethesda, Maryland). A paired Student $t$ test was used for means comparisons of parameters related to deposition between the 2 modalities. The residual radioactivity of the collectors was compared using an unpaired Student $t$ test.

\section{Results}

The anthropometric and lung function parameters of the 6 subjects are presented in Table 1. The results of total and regional lung deposition and extrathoracic deposition are presented in Table 2. Central deposition was lower than peripheral deposition under both conditions, with an $\mathrm{O} / \mathrm{I}$ ratio $>1$ even if the superiority of a mode varies between subjects (Fig. 4). A low extrapulmonary activity was found. Nominal and residual radioactivity were similar in both groups $(P=.99$ and $P=.55$, respectively), with a coefficient of variation of $<6 \%$ for the 2 measurements. The residual activity was $77.5 \pm 5.8$ and $79.1 \pm 1.9 \%$ of the initial activity for peripheral and central deposition, respectively. The mean mass balance was 0.94 and 0.95 for 
Table 2. Radioactivity Deposition Parameters for Central and Peripheral Drug Targeting Nebulization

\begin{tabular}{|c|c|c|c|c|c|c|c|c|}
\hline \multirow{2}{*}{ Parameter } & \multicolumn{2}{|c|}{ IPD (\% WBD) } & \multicolumn{2}{|c|}{ ExD (\% WBD) } & \multicolumn{2}{|c|}{ O/I Ratio } & \multicolumn{2}{|c|}{ PI } \\
\hline & $\mathrm{C}$ & $\mathrm{P}$ & $\mathrm{C}$ & $\mathrm{P}$ & $\mathrm{C}$ & $\mathrm{P}$ & $\mathrm{C}$ & $\mathrm{P}$ \\
\hline Mean $\pm \mathrm{SD}$ & $83.3 \pm 6.5$ & $82.8 \pm 7.3$ & $16.7 \pm 6.5$ & $17.2 \pm 7.3$ & $1.24 \pm 0.21$ & $1.22 \pm 0.14$ & $95.6 \pm 13.5$ & $92.8 \pm 16.1$ \\
\hline Coefficient of variation (\%) & 8 & 9 & 39 & 42 & 17 & 12 & 14 & 17 \\
\hline$P$ & \multicolumn{2}{|c|}{.86} & \multicolumn{2}{|c|}{.86} & \multicolumn{2}{|c|}{.79} & \multicolumn{2}{|c|}{.77} \\
\hline $\begin{array}{l}\mathrm{IPD}=\text { intrapulmonary deposition } \\
\text { WBD }=\text { whole-body radioactivity } \\
\text { ExD }=\text { extrathoracic deposition } \\
\mathrm{O} / \mathrm{I} \text { ratio = outer-to-inner deposition r } \\
\mathrm{PI}=\text { penetration index } \\
\mathrm{C}=\text { central targeting nebulization } \\
\mathrm{P}=\text { peripheral targeting nebulization }\end{array}$ & & & & & & & & \\
\hline
\end{tabular}

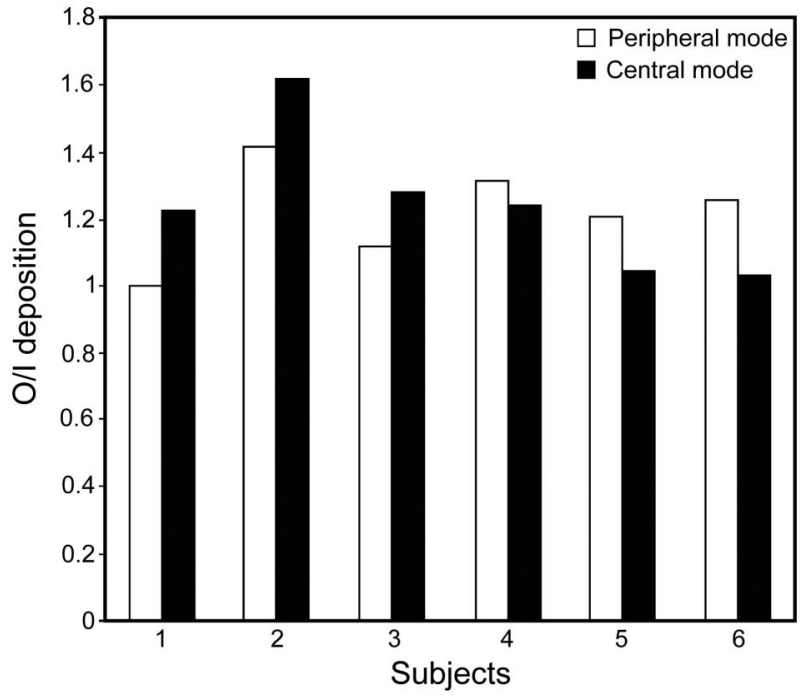

Fig. 4. Ratio of outer lung deposition to inner lung deposition for the 6 subjects and both nebulization modalities (peripheral and central targeting modes). $\mathrm{O}=$ outer lung; I = inner lung.

both modalities. The duration of the nebulization was different depending on the number of inhalations $(445 \pm 41 \mathrm{~s}$ vs $681 \pm 71 \mathrm{~s}$ for peripheral and central deposition, respectively; $P=.002$ ).

\section{Discussion}

In a randomized double-blind controlled trial, we compared the peripheral and central lung deposition by drug targeting nebulization in healthy male volunteers. We have shown that the Akita device delivered a large amount of drug into the peripheral part of the lung independent of the modality but without any difference in lung or regional deposition between both modalities.

Independent of the targeted site of deposition, we measured a high efficiency for the Akita. Indeed, the proportion of the dose reaching the lungs was high compared with the classical nondrug targeting nebulizers. ${ }^{25,26}$ It is consistent with a previous study with 6 subjects with $\alpha 1$ penetration index deficiency. ${ }^{27}$ This improved efficiency is probably related to the electronically guided inspiration $^{25}$ and to the low breathing frequency ${ }^{15}$ generated by the Akita, which are known to be beneficial for lung deposition and to target the peripheral lung as a region of interest. ${ }^{28} \mathrm{~A}$ controlled inhalation also helps patients to improve their inhalation technique, resulting in a better clinical efficacy, as previously shown in children with stable cystic fibrosis. ${ }^{29}$

The extrathoracic deposition related to this high efficiency was low and even lower than in a previous study. ${ }^{28}$ Slow and deep inhalation (as in our protocol) helps to reduce the extrathoracic deposition in comparison with tidal inhalation. ${ }^{30}$ The Akita was demonstrated to deliver $\sim 70 \%$ of the nominal dose to the lung independent of lung disease or severity, ${ }^{28}$ which is much higher than the lung deposition obtained with all other forms of nebulization. However, in our study, this percentage was lower. This reduction is explained by the settings of our program, which stopped the administration after a preset number of inhalations, resulting in a high but similar residual solution in the nebulizer for both modalities. This feature was confirmed by the residual radioactivity measured in the nebulizer. Moreover, lower lung deposition in healthy subjects compared with patients is well known. ${ }^{31}$

This is the first attempt to compare the lung deposition between 2 modalities of drug targeting nebulization (central and peripheral) proposed by the Akita device manufacturer. The peripheral deposition was higher than the central deposition in all experiments and all subjects. This higher peripheral deposition related to the Akita was demonstrated previously, ${ }^{28}$ but the ratio of deposition was never observed in relationship to the specific settings of drug targeting. This piece of information seems important because a better clinical efficacy related to a higher peripheral deposition was previously noted with dornase alfa in 


\section{Drug Targeting Nebulization and Lung Deposition}

patients with cystic fibrosis. ${ }^{29}$ Classically, scintigraphy underestimates the peripheral deposition due to the alveolar spaces included in the inner region due to how regions of interest are defined. ${ }^{32}$ The choice of regions of interest was discussed in a recent recommendation..$^{24}$ Our results confirm that the Akita device offers a better method for drug administration to the peripheral lung compared with other modalities of nebulization, but they suggest that it is the device itself rather than the settings that are supposed to target differentially central or peripheral airways. Indeed, the bolus of air after drug delivery did not improve the deposition in this region, similar to the central targeted nebulization. We postulate that the slow inspiration $(200 \mathrm{~mL} / \mathrm{s})$ guided by the Akita is the key factor promoting the peripheral deposition of a drug. A slow inspiratory flow was previously related to a better peripheral deposition after a single breath of an inert aerosol. ${ }^{21}$ Even if the $\mathrm{O} / \mathrm{I}$ ratio was $>1$ independent of the mode, the highest $\mathrm{O} / \mathrm{I}$ ratio was not related to one of the 2 modalities. It could be explained by the variability of airway geometry between subjects.

Inspiratory period highly influences lung deposition and determines its variability. ${ }^{33}$ In our study, the duration of inspiration was similar for both modalities. The difference in total time of nebulization between the modalities was not related to inspiration but to the number of inhalations. This difference could be clinically important due to the relationship between a long delivery time and poor acceptance of nebulization. ${ }^{34}$

The variability of lung and peripheral deposition can be 4 times higher for spontaneous breathing than for controlled breathing. ${ }^{27}$ The low variability (expressed by the coefficient of variation) we found for intrapulmonary deposition with the Akita confirms the results of previous studies. ${ }^{27,28}$

The penetration index approached $100 \%$. This means that the deposition was uniform throughout the lungs and indirectly confirms the healthy respiratory status of the subjects. The accuracy and precision of the measurements were verified. Indeed, the mean mass balance was close to $100 \%$, as recommended. ${ }^{24}$ This validates the method of attenuation correction.

Some methodological aspects of the study compared with available published data should be addressed. To compare both modalities of nebulization, healthy subjects were recruited per usual practice for evaluating devices. ${ }^{9,35,36}$ Even if the lung deposition in healthy subjects cannot be extrapolated to patients with respiratory disease, it was demonstrated that lung and peripheral deposition was not different using the Akita between healthy subjects and patients with cystic fibrosis. ${ }^{28}$ Moreover, the subjects were their own controls to reduce anatomical, anthropometrical, and respiratory well known influences on lung deposition. For a methodological consideration, only men were re- cruited, even if gender can influence the deposition of inhaled particles. Indeed, even if total lung deposition is comparable between both sexes ${ }^{37,38}$ (except for very small particles, in which deposition is slightly higher for women than for men ${ }^{39}$ ), regional deposition is different depending on gender. ${ }^{40}$ As mentioned previously, electronically guided inhalation eliminates the influence of the breathing pattern. Although a small but statistically sufficient number of subjects were investigated, the group was homogeneous in terms of lung function, probably the main influencing parameter on lung deposition in healthy subjects.

\section{Conclusions}

In conclusion, this study shows for the first time that choosing 2 different specific drug targeting nebulization modes does not influence the amount of drug delivered into the lung in healthy male subjects. Moreover, the selected modes do not modify the site of deposition under the conditions of our study.

\section{REFERENCES}

1. Laube BL. The expanding role of aerosols in systemic drug delivery, gene therapy, and vaccination. Respir Care 2005;50(9):1161-1176.

2. Döring G, Hoiby N. Early intervention and prevention of lung disease in cystic fibrosis: a European consensus. J Cyst Fibros 2004; 3(2):67-91.

3. Ramsey BW, Dorkin HL, Eisenberg JD, Gibson RL, Harwood IR, Kravitz RM, et al. Efficacy of aerosolized tobramycin in patients with cystic fibrosis. N Engl J Med 1993;328(24):1740-1746.

4. Chuchalin A, Csiszér E, Gyurkovics K, Bartnicka MT, Sands D, Kapranov N, et al. A formulation of aerosolized tobramycin (Bramitob) in the treatment of patients with cystic fibrosis and Pseudomonas aeruginosa infection: a double-blind, placebo-controlled, multicenter study. Paediatr Drugs 2007;9(Suppl 1):21-31.

5. Berlana D, Llop JM, Manresa F, Jódar R. Outpatient treatment of Pseudomonas aeruginosa bronchial colonization with long-term inhaled colistin, tobramycin, or both in adults without cystic fibrosis. Pharmacotherapy 2011;31(2):146-157.

6. Clark AR. Understanding penetration index measurements and regional lung targeting. J Aerosol Med Pulm Drug Deliv 2012;25(4): 179-187.

7. Heijerman H, Westerman E, Conway S, Touw D, Döring G. Inhaled medication and inhalation devices for lung disease in patients with cystic fibrosis: a European consensus. J Cyst Fibros 2009;8(5):295315.

8. Byrne NM, Keavey PM, Perry JD, Gould FK, Spencer DA. Comparison of lung deposition of colomycin using the HaloLite and the Pari LC Plus nebulisers in patients with cystic fibrosis. Arch Dis Child 2003;88(8):715-718.

9. Hardy JG, Newman SP, Knoch M. Lung deposition from four nebulizers. Respir Med 1993;87(6):461-465.

10. Mukhopadhyay S, Staddon GE, Eastman C, Palmer M, Davies ER, Carswell F. The quantitative distribution of nebulized antibiotic in the lung in cystic fibrosis. Respir Med 1994;88(3):203-211.

11. Coates AL, Green M, Leung K, Chan J, Ribeiro N, Louca E, et al. Rapid pulmonary delivery of inhaled tobramycin for Pseudomonas infection in cystic fibrosis: a pilot project. Pediatr Pulmonol 2008; 43(8):753-759. 


\section{Drug Targeting Nebulization and Lung Deposition}

12. Ilowite JS, Gorvoy JD, Smaldone GC. Quantitative deposition of aerosolized gentamicin in cystic fibrosis. Am Rev Respir Dis 1987; 136(6): 1445-1449.

13. Bauer A, McGlynn P, Bovet LL, Mims PL, Curry LA, Hanrahan JP. The influence of breathing pattern during nebulization on the delivery of arformoterol using a breath simulator. Respir Care 2009; 54(11):1488-1492.

14. Coates AL, Allen PD, MacNeish CF, Ho SL, Lands LC. Effect of size and disease on estimated deposition of drugs administered using jet nebulization in children with cystic fibrosis. Chest 2001;119(4): 1123-1130.

15. Häkkinen AM, Uusi-Heikkilä H, Järvinen M, Saali K, Karhumäki L. The effect of breathing frequency on deposition of drug aerosol using an inhalation-synchronized dosimeter in healthy adults. Clin Physiol 1999;19(3):269-274.

16. Newman SP, Woodman G, Clarke SW. Deposition of carbenicillin aerosols in cystic fibrosis: effects of nebuliser system and breathing pattern. Thorax 1988;43(4):318-322.

17. Diot P, Dequin PF, Rivoire B, Gagnadoux F, Faurisson F, Diot E, et al. Aerosols and anti-infectious agents. J Aerosol Med 2001;14(1): 55-64.

18. Dessanges JF. A history of nebulization. J Aerosol Med 2001;14(1): 65-71.

19. Geller DE, Kesser KC. The I-neb Adaptive Aerosol Delivery System enhances delivery of $\alpha 1$-antitrypsin with controlled inhalation. J Aerosol Med Pulm Drug Deliv 2010;23(Suppl 1):S55-S59.

20. Brand P, Friemel I, Meyer T, Schulz H, Heyder J, Häubetainger K. Total deposition of therapeutic particles during spontaneous and controlled inhalations. J Pharm Sci 2000;89(6):724-731.

21. Brand P, Meyer T, Häussermann S, Schulte M, Scheuch G, Bernhard $\mathrm{T}$, et al. Optimum peripheral drug deposition in patients with cystic fibrosis. J Aerosol Med 2005;18(1):45-54.

22. Coates AL, Dinh L, MacNeish CF, Rollin T, Gagnon S, Ho SL, Lands LC. Accounting for radioactivity before and after nebulization of tobramycin to insure accuracy of quantification of lung deposition. J Aerosol Med 2000;13(3):169-178.

23. Miller MR, Hankinson J, Brusasco V, Burgos F, Casaburi R, Coates A, et al. Standardisation of spirometry. Eur Respir J 2005;26(2):319338.

24. Newman S, Bennett WD, Biddiscombe M, Devadason SG, Dolovich $\mathrm{MB}$, Fleming J, et al. Standardization of techniques for using planar (2D) imaging for aerosol deposition assessment of orally inhaled products. J Aerosol Med Pulm Drug Deliv 2012;25(Suppl 1):S10S28.

25. Köhler E, Sollich V, Schuster-Wonka R, Jorch G. Lung deposition after electronically breath-controlled inhalation and manually triggered conventional inhalation in cystic fibrosis patients. J Aerosol Med 2005;18(4):386-395.
26. Lenney W, Edenborough F, Kho P, Kovarik JM. Lung deposition of inhaled tobramycin with eFlow rapid/LC Plus jet nebuliser in healthy and cystic fibrosis subjects. J Cyst Fibros 2011;10(1):9-14.

27. Brand P, Beckmann H, Maas Enriquez M, Meyer T, Müllinger B, Sommerer K, et al. Peripheral deposition of $\alpha 1$-protease inhibitor using commercial inhalation devices. Eur Respir J 2003;22(2):263267.

28. Brand P, Schulte M, Wencker M, Herpich CH, Klein G, Hanna K, Meyer T. Lung deposition of inhaled $\alpha 1$-proteinase inhibitor in cystic fibrosis and $\alpha 1$-antitrypsin deficiency. Eur Respir J 2009;34(2): 354-360.

29. Bakker EM, Volpi S, Salonini E, van der Wiel-Kooij EC, Sintnicolaas CJ, Hop WC, et al. Improved treatment response to dornase alfa in cystic fibrosis patients using controlled inhalation. Eur Respir J 2011;38(6):1328-1335.

30. Nikander K, Prince I, Coughlin S, Warren S, Taylor G. Mode of breathing-tidal or slow and deep-through the I-neb Adaptive Aerosol Delivery (AAD) system affects lung deposition of ${ }^{99 \mathrm{~m}}$ Tc-DTPA. J Aerosol Med Pulm Drug Deliv 2010;23(Suppl 1):S37-S43.

31. Darquenne C. Aerosol deposition in health and disease. J Aerosol Med Pulm Drug Deliv 2012;25(3):140-147.

32. Biddiscombe MF, Meah SN, Underwood SR, Usmani OS. Comparing lung regions of interest in gamma scintigraphy for assessing inhaled therapeutic aerosol deposition. J Aerosol Med Pulm Drug Deliv 2011;24(3):165-173.

33. Bennett WD, Smaldone GC. Human variation in the peripheral airspace deposition of inhaled particles. J Appl Physiol 1987;62(4): 1603-1610.

34. Kendrick AH, Smith EC, Wilson RS. Selecting and using nebuliser equipment. Thorax 1997;52(Suppl 2):S92-S101.

35. Pitance L, Vecellio L, Leal T, Reychler G, Reychler H, Liistro G. Delivery efficacy of a vibrating mesh nebulizer and a jet nebulizer under different configurations. J Aerosol Med Pulm Drug Deliv 2010;23(6):389-396

36. Reychler G, Keyeux A, Cremers C, Veriter C, Rodenstein DO, Liistro G. Comparison of lung deposition in two types of nebulization: intrapulmonary percussive ventilation vs jet nebulization. Chest 2004;125(2):502-508.

37. Bennett WD, Zeman KL, Kim C. Variability of fine particle deposition in healthy adults: effect of age and gender. Am J Respir Crit Care Med 1996;153(5):1641-1647.

38. Kim CS, Hu SC. Total respiratory tract deposition of fine micrometersized particles in healthy adults: empirical equations for sex and breathing pattern. J Appl Physiol 2006;101(2):401-412.

39. Jaques PA, Kim CS. Measurement of total lung deposition of inhaled ultrafine particles in healthy men and women. Inhal Toxicol 2000; 12(8):715-731.

40. Kim CS, Hu SC. Regional deposition of inhaled particles in human lungs: comparison between men and women. J Appl Physiol 1998;84(6):1834-1844.

This article is approved for Continuing Respiratory Care Education credit. For information and to obtain your CRCE

(free to AARC members) visit www.rcjournal.com

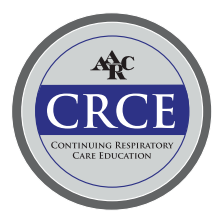

